\title{
Helium and its Properties.*
}

\section{By the Right Hon. Lord Rutherford, O.M., F.R.S.}

$\mathrm{T}$ HE history of the discovery of helium presents some features of unusual dramatic interest. During an eclipse in 1868, Jansen and Lockyer noticed that the visual spectrum of the sun's chromosphere showed a bright yellow line of unknown origin. Later it was found that this line and others that accompanied it appeared not only in the sun, but also in many of the stars. Lockyer suggested that these lines were due to an undiscovered element, to which he gave the name helium.

Shortly after the discovery of argon, Sir Henry Miers sent a letter (Feb. 1, 1895) to Ramsay pointing out that the American analyst Hillebrande had observed that a considerable quantity of gas, supposed to be nitrogen, was liberated by solution of certain minerals containing uranium. Miers suggested that the gas might prove to be argon and not nitrogen. Following his suggestion, Ramsay purchased about a gram of the mineral cleveite from a dealer for three shillings and sixpence and proceeded to purify the gases evolved and to examine their spectra. A number of new lines were observed and a spectrum tube containing the new gas temporarily called crypton by Ramsay was sent to Sir William Crookes for a detailed study of its spectrum. Crookes reported tersely, "Crypton is Helium; come and see it". Less than two months had elapsed from the receipt of Miers's letter to the announcement in the Paris Academy of Sciences, on March 26, 1895, of the discovery of helium on the earth-a discovery of profound significance to the development of physics. It was soon shown that helium is a monatomic gas of density about twice that of hydrogen and of atomic weight 4 . We now know that it is the first of that remarkable group of inert monatomic gases, namely, helium, neon, argon, krypton, xenon, and the radioactive emanations, which have played such an important part in helping to fix the arrangements of the electrons in the outer atom.

In 1903, Ramsay and Soddy found that helium was produced by the transformation of radium, and, as a result of a series of researches, Rutherford showed that the $a$-particles which are ejected with great velocity from radioactive atoms are identical with helium nuclei. It is probable that the greater part, if not all, of the helium found in the earth and in the natural gases escaping from the earth owes its origin to the $\alpha$-particles expelled from the radioactive elements during their transformation in the earth's crust.

It now seems clear that the helium nucleus of resultant charge 2 is remarkably stable and is in some way built up by the combination of four protons and two electrons. The loss of mass in this combination shows that a very large amount of energy, probably in the form of penetrating $\gamma$-rays, is emitted during the process. It can be

* Abstract of the Friday evening discourse delivered at the Royal Institution on March 27.

No. 3221, VoL. 128] calculated that the energy released in the formation of one pound of helium from hydrogen corresponds to the energy liberated in the complete combustion of 10,000 tons of coal. There can be no doubt that helium is formed from hydrogen under some, as yet unknown, conditions in the stellar system. However, it has not yet been found possible to produce helium from hydrogen under laboratory conditions. Millikan claims that the absorbable part of the cosmic rays must be attributed to the radiation emitted in the formation of helium in the depths of space.

The $\alpha$-particle or helium nucleus has proved of great importance in extending our knowledge of the structure of nuclei, and it is now believed that the nuclei of the heavier elements are composed mainly of $\alpha$-particles and electrons, although a few free protons may also be present. The bombardment of light elements by swift $\alpha$-particles has given us the first definite proof of the transformation of some of the ordinary elements by artifical methods.

Helium is the most difficult of all gases to produce in liquid form. This was first accomplished by the late Prof. Kamerlingh Onnes in his laboratory at Leyden in 1908 by using liquid hydrogen as a cooling agent. Helium liquefies at a temperature of about $4^{\circ}$ absolute, and is a clear colourless liquid of density about $0 \cdot 15$. In recent years, by using helium under pressure, Prof. Keesom, of Leyden, has succeeded in solidifying helium. By the evaporation of liquid helium at low pressure, temperatures so low as $1^{\circ}$ absolute have been obtained.

Liquid helium thus provides a suitable method for the study of the effect of low temperatures on the properties of matter. One of the most striking observations is that certain metals become superconductors at such low temperatures and show little if any resistance to the passage of an electrical current. Several cryogenic laboratories have been instituted for the study of the effects of low temperatures on matter. Apart from the well-known and well-equipped laboratory at Leyden, Prof. J. C. McLennan liquefied helium in the University of Toronto in 1923, while in 1925 a similar department was instituted in the Reichsanstalt, Berlin. Researches in the properties of matter at the lowest possible temperatures have already added widely to our knowledge in a number of important directions.

Helium is present in our atmosphere in small quantity, about one part in 185,000 by volume. In the early days, most of the helium used for experimental purposes was obtained by heating radioactive minerals and particularly the mineral thorianite from Ceylon. It was also found that helium is often present in considerable quantity in the gases escaping from hot springs and the natural gases from the earth's crust.

In 1914, Sir Richard Threlfall suggested to the 
Board of Inventions of the Admiralty that, on account of its lightness and non-inflammability, helium might prove of great service for balloons and airships. Prof. J. C. McLennan was asked to initiate experiments to see whether helium could be separated in quantity from the natural gases escaping from the earth in certain districts of Canada which were known to contain about 1 per cent of helium by volume. Arrangements were made on a semi-commercial scale to purify the helium by liquefying the methane and other gases present. The impure helium was concentrated in the non-liquefying portion. In this way, many thousands of cubic feet of helium were prepared and transported in cylinders at high pressure. About the same time, the Bureau of Mines of the U.S.A. began similar experiments on a large scale, using the natural gases of Texas, which are rich in helium. Large quantities of helium were separated by liquefaction methods, and the cost of the helium was found to be sufficiently low to use it in airships in the place of hydrogen. Apart from the cost of transport, the expense of separation of helium decreases with the concentration of the helium in the natural gases. The commercial prospects of the use of helium in airships and other purposes have led to a search for rich concentrations of helium.

While most natural gases contain less than I per cent of helium, much richer mixtures have been recently found by boring. One source in Grand County, Utah, has a helium content of 7 per cent. Another was found in Colorado yielding as high as 8 per cent. The gas appears at a depth of about
950 feet in what is known as the Wingate sand. The Helium Company has erected a plant at Thatcher, Colorado, for purification of the helium obtained from this source. Analysis shows that the gas contains 15 per cent carbon dioxide, 8 per cent helium, 1.75 per cent methane, and the rest nitrogen. The plant installed has a capacity of about 600,000 cubic feet of the gas per day, corresponding to a possible annual production of 12 million cubic feet of helium. With such a rich helium mixture, the cost of separation should be much less than in the plants treating the natural gases of much lower helium content.

It is possible that similar rich concentrations may be found on the eastern slopes of the Rocky Mountains in Canada. A small gas field was found a few years ago not far from Toronto which had a content of 0.8 per cent helium. The rights of those wells have been secured for the University of Toronto in order to have an ample supply of helium for cryogenic experiments in the laboratories.

At the time of its discovery, helium was considered to be a rare gas and a litre of helium was a precious possession. The helium originally employed by Kamerlingh Onnes for the liquefaction of helium was painfully obtained by heating radioactive minerals. This is in striking contrast to the position to-day, when the annual production of helium is measured by millions of cubic feet, and where sufficient quantity will be available at a comparatively low cost for filling several large airships now in course of construction.

\section{A. M. Liapounov, I857-I9I8.}

\section{By A. J. Pressland.}

$\mathrm{F}$ ROM time to time, French versions of the writings of A. M. Liapounov have become available to the scientific public; but the obituary notice in the Proceedings of the Academy of Sciences in Leningrad (1919, p. 367, by Stekloff), and other papers, are in Russian. Quite recently the Academy has published two brochures, one a biography and the other a general survey of Liapounov's work on Chebichev's problem, and the following is a digest of this material.

A. M. Liapounov, the eldest son of M. V. Liapounor and a grandson of V. A. Liapounov, registrar of the University of Kazan, was born on May 25, 1857. Six of his immediate kinsmen attained to academic eminence. His father, an astronomer of repute, died in 1868, leaving a young family. So the boy was brought up for a time by a married aunt, in whose house he increased his acquaintanco with people of intellectual distinction. In 1870 he entered the third class of the gymnasium of Nishni-Novgorod, where he was taught Latin, Greek, and elementary science. He read widely, Buckle, Draper, Humboldt, Réclus, and Karl Ritter being his favourite authors, and he developed a love for exact science. The national idealism that was then popular did not appeal to him, but he was attracted by the study of economics and the theory of the struggle for existence.

In 1876 Liapounov passed out of the gymnasium with the highest distinction and matriculated at St. Petersburg, where at first he attended the lectures of Mendeléeff, which he soon forsook for those of Chebichev. To the latter is due the inspiration of Liapounov's researches. Chebichev laid stress on Anschauung and Realien, holding that research work was valuable only when it lent itself to application, and theory useful only when it emerged from a consideration of particular cases.

Chebichev directed Liapounov to the problem of determining the free surface of a liquid gravitational mass that was rotating about an axis. $\mathrm{He}$ had already proposed the problem to prominent students such as Zolotarev and Sophia Kovalev. skaya, but no one of them seems to have made noteworthy progress. The problem has a long history. Newton noted that an ellipsoid of revolution can be a surface of equilibrium, but Maclaurin was the first to give it serious consideration; on this account an ellipsoid of revolution which is a form of equilibrium is called an ellipsoid of Maclaurin. D'Alembert showed that for every angular velocity less than a given limit there were 